\title{
Reactive Sputtering of Bismuth Vanadate Photoanodes for Solar Water Splitting
}

Le Chen, ${ }^{\dagger, \ddagger}$ Esther Alarcón-Lladó, ${ }^{\dagger, \ddagger, \|}$ Mark Hettick, ${ }^{\dagger, \ddagger, \perp}$ Ian D. Sharp, ${ }^{\dagger, \S}$ Yongjing Lin, ${ }^{\dagger, \ddagger, \perp}$ Ali Javey, ${ }^{\dagger, \ddagger, \perp}$ and Joel W. Ager $*,+,+$

$\dagger$ Joint Center for Artificial Photosynthesis, Lawrence Berkeley National Laboratory, Berkeley, California 94720, United States

${ }^{\ddagger}$ Materials Sciences Division, Lawrence Berkeley National Laboratory, Berkeley, California 94720, United States

${ }^{\S}$ Physical Biosciences Division, Lawrence Berkeley National Laboratory, Berkeley, California 94720, United States

"École Polytechnique Fédérale de Lausanne, Lausanne, Switzerland

${ }^{\perp}$ Department of Electrical Engineering and Computer Sciences, University of California, Berkeley, Berkeley, California 94720 , United States

\section{Supporting Information}

ABSTRACT: Bismuth vanadate $\left(\mathrm{BiVO}_{4}\right)$ has attracted increasing attention as a photoanode for photoelectrochemical (PEC) water splitting. It has a band gap in the visible light range $(2.4-2.5 \mathrm{eV})$ and a valence band position suitable for driving water oxidation under illumination. While a number of methods have been used to make $\mathrm{BiVO}_{4}$ photoanodes, scalable thin film deposition has remained relatively underexplored. Here, we report the synthesis of $\mathrm{BiVO}_{4}$ thin films by reactive sputtering. The use of separate $\mathrm{Bi}$ and $\mathrm{V}$ sputtering targets allows control of the $\mathrm{Bi} / \mathrm{V}$ ratio in the film. Under optimized, slightly V-rich conditions, monoclinic phase $\mathrm{BiVO}_{4}$ with photoactivity for water oxidation is obtained. The highest photocurrents, ca. $1 \mathrm{~mA} \mathrm{~cm}{ }^{-2}$ at the reversible $\mathrm{O}_{2} / \mathrm{H}_{2} \mathrm{O}$ potential with simulated AM $1.5 \mathrm{G}$ illumination, are obtained with bilayer $\mathrm{WO}_{3} / \mathrm{BiVO}_{4}$, where the $\mathrm{WO}_{3}$ serves as a hole-blocking layer.

\section{INTRODUCTION}

Bismuth vanadate $\left(\mathrm{BiVO}_{4}\right)$ has been studied since the late 1990 s as a water oxidation photocatalyst ${ }^{1,2}$ and also as an alternative photocatalyst to $\mathrm{TiO}_{2}$ for organic pollutant removal. ${ }^{3,4}$ Recently, there has been growing interest in using $\mathrm{BiVO}_{4}$ as a photoanode for photoelectrochemical water splitting. ${ }^{5,6} \mathrm{BiVO}_{4}$ has a number of attractive material properties for this purpose. It has a band gap in the visible region of the electromagnetic spectrum, 2.4-2.5 eV, is composed of abundant and nontoxic elements, and has been reported to drive water oxidation with an onset potential of up to $0.3 \mathrm{~V}$ vs $\mathrm{RHE}\left(0.9 \mathrm{~V}\right.$ vs the reversible $\mathrm{O}_{2} / \mathrm{H}_{2} \mathrm{O}$ potential), ${ }^{7,8}$ which makes it attractive for pairing with hydrogen-producing photocathodes in a tandem water splitting arrangement. ${ }^{6,9}$

Park et al. have recently reviewed the current status of $\mathrm{BiVO}_{4}$ photoanodes. ${ }^{6}$ For use in tandem water splitting geometry, it must be possible to electrically contact the $\mathrm{BiVO}_{4}$ in either a thin film or equivalent nanostructured configuration. The most widely used synthesis methods use solution phase chemistry coupled with spin-coating or spray pyrolysis to make $\mathrm{BiVO}_{4}$ films. ${ }^{10-14}$ Electrochemical deposition has also been reported. ${ }^{6,15,16}$ For unmodified $\mathrm{BiVO}_{4}$, reported photocurrents for water oxidation with AM1.5 illumination are lower than 1 $\mathrm{mA} \mathrm{cm}{ }^{-2}$, $76-18$ which is less than $15 \%$ of the theoretical maximum for a $2.4 \mathrm{eV}$ absorber $\left(7.5 \mathrm{~mA} / \mathrm{cm}^{2}\right)$. Known issues with $\mathrm{BiVO}_{4}$ include poor electron transport, as evidenced by higher photocurrents for back as opposed to front illumination and slow water oxidation kinetics. ${ }^{15,19}$ Doping, cocatalysts such as Co-Pi and hole-blocking back contacts have been found to improve performance significantly. ${ }^{13,14,20}$

Physical vapor deposition (PVD) methods for the synthesis of $\mathrm{BiVO}_{4}$ have been explored relatively little. ${ }^{17,21}$ Sputtering is a commercially available and scalable physical vapor deposition process which has been used to make a number of metal oxide or nitride thin film materials such as $\mathrm{TiO}_{2}, \mathrm{WO}_{3}$, and $\mathrm{TaON}$ for photocatalytic and photoelectrochemical applications. ${ }^{2-24}$ Some potential advantages of sputter deposition are control of stoichiometry, film uniformity and adhesion, and ability to make a dense film for the evaluation of fundamental properties. In this study, we report the synthesis of high quality $\mathrm{BiVO}_{4}$ thin films for PEC application by reactive sputtering. Bi and $\mathrm{V}$ have very different sputtering yields, so separate $\mathrm{Bi}$ and $\mathrm{V}$ precursor targets were used to produce the desired phase of $\mathrm{BiVO}_{4}$ and control over the $\mathrm{Bi} / \mathrm{V}$ ratio. We find that a slight $\mathrm{V}$ excess yields the best water oxidation performance, which can be further improved by hole-blocking back contact. ${ }^{18,19}$

Received: June 18, 2013

Revised: September 20, 2013

Published: September 23, 2013 


\section{EXPERIMENTAL METHODS}

Synthesis. All depositions were performed with an AJA International ATC Orion 5 sputtering machine equipped with a load lock. Use of a single $\mathrm{BiVO}_{4}$ target was not successful in producing stoichiometric $\mathrm{BiVO}_{4}$ films as $\mathrm{Bi}$ was preferentially depleted from the target. Instead, we used a cosputtering approach using separate two inch diameter bismuth oxide $\left(\mathrm{Bi}_{2} \mathrm{O}_{3}, 99.9 \%\right)$ and vanadium $(\mathrm{V}, 99.99 \%)$ targets, as shown in Figure 1. Because of the large thermal conductivity disparity

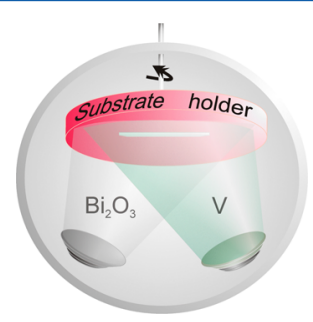

Figure 1. Illustration of the cosputtering of $\mathrm{Bi}_{2} \mathrm{O}_{3}$ and $\mathrm{V}$ to deposit $\mathrm{BiVO}_{4}$ thin films.

between $\mathrm{Bi}_{2} \mathrm{O}_{3}\left(0.7-0.9 \mathrm{~W} \cdot \mathrm{m}^{-1} \cdot \mathrm{K}^{-1}\right)$ and $\mathrm{V}\left(30.7 \mathrm{~W} \cdot \mathrm{m}^{-1}\right.$. $\left.\mathrm{K}^{-1}\right),{ }^{25}$ two different target power supplies were used to independently tune the $\mathrm{Bi}$ and $\mathrm{V}$ sputtering rates. We found that the combination of a high-power direct current (dc) power supply for the vanadium target source and a radio frequency (rf) power supply for the bismuth oxide target yielded the greatest degree of compositional control. Typical operation power range was $35-40 \mathrm{~W}$ for the $\mathrm{Bi}_{2} \mathrm{O}_{3}$ rf power supply and 180-185 W for the $\mathrm{V}$ dc power supply.

A mixture of $\mathrm{Ar}$ and $\mathrm{O}_{2}$ was used for reactive sputtering. We found that the $\mathrm{O}_{2}$ partial pressure affected the sputtering yield, especially for the $\mathrm{V}$ target. Lower $\mathrm{O}_{2}$ partial pressures increased the sputtering yields for vanadium. Following optimization, we selected a total pressure of $5.1 \mathrm{mT}$ Torr, with partial pressures of $4.5 \mathrm{mTorr} \mathrm{Ar}$ and $0.6 \mathrm{mTorr}_{2}$, for all films reported in this work. These conditions resulted in a deposition rate of approximately $2.5 \mathrm{~nm} / \mathrm{min}$. The indium doped tin oxide (ITO) coated glass substrates were held at room temperature during deposition, and the resulting films were annealed in a tube furnace under air at $500{ }^{\circ} \mathrm{C}$ for $2 \mathrm{~h}$.

Characterization and Measurement. The morphology and bulk elemental composition ( $\mathrm{Bi}$ to $\mathrm{V}$ atomic ratio) of the films were characterized using an FEI Quanta 200 FEG scanning electron microscope (SEM) with a Bruker Quantax energy dispersive spectroscopy (EDS) attachment. Film thickness was measured using a DEKTAK IA profilometer (Veeco) to determine the step height at a masked edge. Bulk crystalline structure of the films was characterized using a Rigaku Smartlab X-ray diffractometer. Phase assignments were made based on the Joint Committee on Powder Diffraction Standards (JCPDS) database. Additional structural characterization was achieved via Raman spectroscopy using a Horiba Yvon Jobin LabRAM HR confocal Raman microscope with a laser excitation wavelength of $633 \mathrm{~nm}$ and power of $0.1-0.3$ $\mathrm{mW}$ at the objective (spot size of approximately $1 \mu \mathrm{m}$ ). The optical absorbance spectrum was measured by a Shimadzu SolidSpec-3700 UV-vis-NIR Spectrophotometer.

Surface elemental analysis was carried out by X-ray photoelectron spectroscopy (XPS) using a monochromatized $\mathrm{Al} \mathrm{K} \alpha$ source $(h \nu=1486.6 \mathrm{eV})$, operated at $225 \mathrm{~W}$, on a Kratos Axis Ultra DLD system at a takeoff angle of $0^{\circ}$ relative to the surface normal. A pass energy of $20 \mathrm{eV}$, corresponding to an instrument resolution of approximately $600 \mathrm{meV}$, was used for narrow scan spectra. Survey spectra were collected with a pass energy of $80 \mathrm{eV}$. Spectral fitting was achieved using Casa XPS analysis software. Core level positions were calibrated to the primary C 1 s core level position of $284.8 \mathrm{eV}$, and curves were fit with quasi-Voigt lines following Shirley background subtraction.

Photoelectrochemical (PEC) characterization was carried out using a BioLogic SP-300 potentiostat, in a three-electrode configuration, with a $\mathrm{BASi} \mathrm{RE} 5 \mathrm{~B} \mathrm{Ag} / \mathrm{AgCl}$ reference electrode, platinum mesh counter electrode, and the sputtered $\mathrm{BiVO}_{4}$ films as the working electrode, in a quartz-windowed cell. The illumination source for $J-V$ characterization was a Solar Light 16S-300-005 solar simulator equipped with an AM1.5 filter set. The light intensity of $100 \mathrm{~mW} / \mathrm{cm}^{2}$ was adjusted and calibrated using a Solar Light PMA-2100 radiometer and a PMA-2144 pyranometer. The electrolyte used for all measurements was 0.5 $\mathrm{M} \mathrm{Na}_{2} \mathrm{SO}_{4}$ in $0.1 \mathrm{M} \mathrm{K}_{2} \mathrm{HPO}_{4}$ buffer solution ( $\mathrm{pH} 7$ ).

Spectrally resolved photocurrents for incident photon to charge conversion efficiency (IPCE) determination were generated using a Newport 150W Xe lamp and an Oriel Cornerstone $1 / 8 \mathrm{~m}$ monochromator with $1.5 \mathrm{~mm}$ slits, yielding a spectral resolution of better than $0.5 \mathrm{~nm}$. A beam splitter, together with a Thorlabs FDS1010-CAL calibrated Si photodiode, was used to monitor the intensity of the monochromatic output during the measurement. In order to ensure accurate measurement, the incident light spot under-filled both the sample and reference diode. A Gamry Reference 600 potentiostat was used in combination with a three-electrode electrochemical cell to maintain the sample at the reported potentials and to measure the current of the photoanode. The IPCE was then calculated based on the following formula: ${ }^{14,26}$

$$
\operatorname{IPCE}(\%)=\frac{1240 \times j_{\mathrm{ph}}\left(\frac{\mathrm{mA}}{\mathrm{cm}^{2}}\right)}{I_{\text {incident }}\left(\frac{\mathrm{mW}}{\mathrm{cm}^{2}}\right) \times \lambda(\mathrm{nm})} \times 100 \%
$$

where $j_{\mathrm{ph}}$ is the measured photocurrent density in $\mathrm{mA} / \mathrm{cm}^{2}$, $I_{\text {incident }}$ is the incident light intensity in $\mathrm{mW} / \mathrm{cm}^{2}$, and $\lambda$ is the incident photon wavelength in $\mathrm{nm}$.

\section{RESULTS/DISCUSSION}

Since near-stoichiometric films of $\mathrm{BiVO}_{4}$ possess optical and electronic properties that are desirable for photoelectrochemical water splitting, we primarily explored $\mathrm{Bi}$ to $\mathrm{V}$ ratios within the compositional range of $40 / 60$ to $60 / 40$, with a goal of forming monoclinic $\mathrm{BiVO}_{4}$ as the main product. In the following discussion, we will concentrate on the properties of three representative films with $\mathrm{Bi} / \mathrm{V}$ ratios of approximately 61/ $39,42 / 58$, and $49.2 / 50.8$, as determined by EDS. For each sample, we selected multiple points at different regions of the sample for EDS measurement, and the measured Bi to $\mathrm{V}$ ratios were consistent to within the range of experimental error, indicating that the films are compositionally uniform. These three films with different $\mathrm{Bi}$ to $\mathrm{V}$ ratios will be referred to as $\mathrm{Bi}$ rich, $\mathrm{V}$-rich, and stoichiometric for the remainder of this article. However, we note that the stoichiometric $\mathrm{BiVO}_{4}$ film contains a slight excess of $\mathrm{V}$, which will be discussed in greater detail below. Unless otherwise noted, all samples are approximately $100 \mathrm{~nm}$ thick.

Scanning electron microscopy (SEM) was used to determine the morphologies of the sputtered thin films as a function of composition. As shown in Figure 2, all films displayed grains 

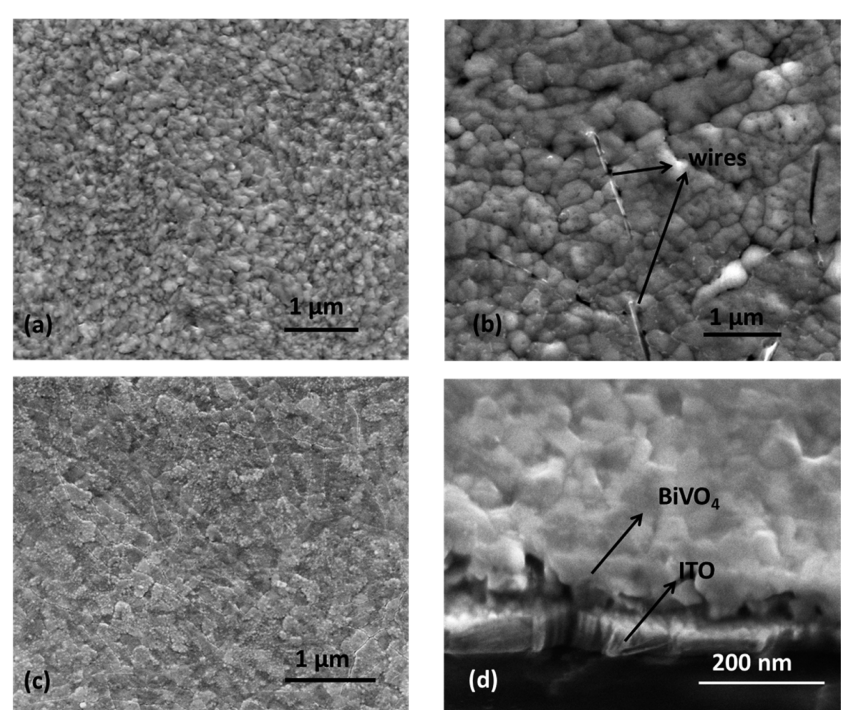

Figure 2. SEM images of reactively sputtered bismuth vanadium oxide thin films with Bi-rich (a), V-rich (b), and stoichiometric $\left(\mathrm{BiVO}_{4}\right)(\mathrm{c})$ compositions. (d) Thirty degree tilt view image of $c$.

indicative of polycrystalline structures. The stoichiometric film (Figure 2c) was characterized by smooth and distinctive grains of a few hundred nanometers in size, whereas the Bi-rich film (Figure 2a) exhibited a rougher surface with less distinctive grain boundaries. The V-rich film also displayed a polycrystalline structure; however, the size of the grains was much bigger but not as uniform as that for the two other samples. Furthermore, some wire-like structures, which resemble the morphology of $\mathrm{V}_{2} \mathrm{O}_{5}$, were observed. Indeed, additional characterization, discussed below, confirmed the presence of the $\mathrm{V}_{2} \mathrm{O}_{5}$ impurity phase in these films. Figure $2 \mathrm{~d}$ shows the cross-section image of the stoichiometric $\mathrm{BiVO}_{4}$ film. As indicated in the figure, the film thickness is about $100 \mathrm{~nm}$, and the film is continuous and dense.

Figure 3 shows XRD spectra from the Bi-rich, V-rich, and stoichiometric films deposited on ITO-coated glass. Since the films are thin $(100 \mathrm{~nm})$, peaks from the ITO substrate were also observed, as indicated by X's in the figure. The primary crystal structure of all 3 films is the monoclinic scheelite phase (vertical dashed lines), which is the most active $\mathrm{BiVO}_{4}$ phase for photocatalysis or photoelectrochemical water split-

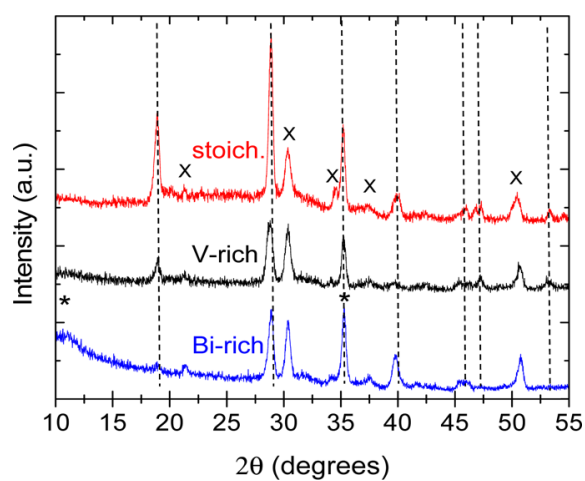

Figure 3. X-ray diffractograms of the Bi-rich (blue), V-rich (black), and stoichiometric (red) sputtered films. The $\mathrm{X}$ labeled peaks are from the ITO substrate, and the vertical dashed lines indicate the peaks from the monoclinic $\mathrm{BiVO}_{4}$ structure. The “*” labeled peaks could arise or include contributions from $\mathrm{Bi}_{2} \mathrm{VO}_{5.5}$. ting. ${ }^{10,27,28}$ For the Bi-rich film, in addition to the pattern of the $\mathrm{BiVO}_{4}$ monoclinic structure, a weak and broad peak appears near $2 \theta$ values of $11-12^{\circ}$. This can be assigned to the $\mathrm{Bi}_{2} \mathrm{VO}_{5.5}$ (002) reflection, showing that excess $\mathrm{Bi}$ can produce phase segregation in the film. We also suspect that the peak at a $2 \theta$ value of $35^{\circ}$ may include combined contributions from the $\mathrm{BiVO}_{4}(002)$ and $\mathrm{Bi}_{2} \mathrm{VO}_{5.5}$ (006) reflections. For the V-rich film, we do not observe evidence of phase segregation (e.g., formation of crystalline $\mathrm{V}_{2} \mathrm{O}_{5}$ ) in XRD, but we do using Raman spectroscopy, as discussed below. In both the off-stoichiometric films, the dominant $\mathrm{BiVO}_{4}$ (121) peak near $28^{\circ}$ is shifted slightly to a lower diffraction angle, indicating an increase of the lattice constant due to the addition of excess $\mathrm{Bi}$ or $\mathrm{V}$. We also note that there is a relative peak intensity reduction for some of the minor peaks (e.g., $(011) /(110)$ peak near $18^{\circ}$ for the Birich sample and $(211) /(112)$ peak near $40^{\circ}$ for the V-rich sample) as compared to the stoichiometric film, suggesting that some growth orientations might be suppressed by additional $\mathrm{Bi}$ or $\mathrm{V}$ incorporation.

Raman spectra of V-rich, Bi-rich, and stoichiometric sputtered thin films are shown in Figure 4. All films have

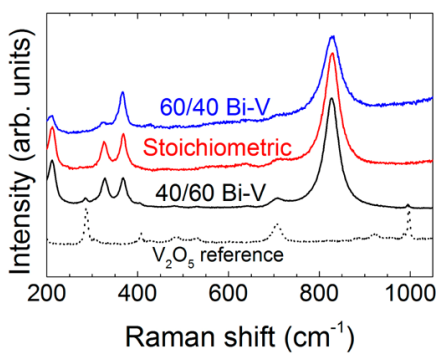

Figure 4. Micro-Raman spectra of Bi-rich (blue), V-rich (red), and stoichiometric (black) sputtered films. The spectrum of $\mathrm{V}_{2} \mathrm{O}_{5}$ reference material is also shown (dotted line).

main peaks at around $212,327,368,640,710$, and $828 \mathrm{~cm}^{-1}$, corresponding to the Raman active vibrational modes of monoclinic $\mathrm{BiVO}_{4} \cdot{ }^{12,15,28,29}$ The spectrum from stoichiometric $\mathrm{BiVO}_{4}$ includes only these spectral contributions and is consistent with a pure monoclinic phase film. For the Bi-rich film, the characteristic $\mathrm{BiVO}_{4}$ Raman features decrease in intensity and become broader. We did not detect the additional bands expected for either the Raman mode of the $\alpha$-phase $\mathrm{Bi}_{2} \mathrm{O}_{3}$ material $\left(306 \mathrm{~cm}^{-1}\right)$ or the ferroelectric $\mathrm{Bi}_{2} \mathrm{VO}_{5.5}(850$ $\mathrm{cm}^{-1}$ ), as have been reported previously for strongly offstoichiometric films. ${ }^{30}$ For the V-rich film, we observe additional weak but sharp lines at 400 and $980 \mathrm{~cm}^{-1}$, which become even more intense in films with lower $\mathrm{Bi} / \mathrm{V}$ ratios. These peaks match the frequencies of the Raman-active vibrational modes of $\mathrm{V}_{2} \mathrm{O}_{5}$ and are consistent with the wirelike features in Figure $2 \mathrm{~b}$. In summary, while there is no evidence of phase segregation in the stoichiometric films, we observe $\mathrm{Bi}_{2} \mathrm{VO}_{5.5}$ and $\mathrm{V}_{2} \mathrm{O}_{5}$ impurity phases in the Bi-rich and V-rich films.

The surface chemical compositions of sputtered BVO thin films were investigated using XPS. As shown in Figure 5, XPS survey spectra confirm the presence of the elemental constituents, $\mathrm{Bi}, \mathrm{V}$, and $\mathrm{O}$, of the deposited films. The presence of adventitious carbon allowed for calibration of the binding energy for each sample, using a standard C 1s position of 284.8 $\mathrm{eV}$. No significant contribution from $\mathrm{Sn}$ of the underlying ITO film was observed, indicating that all films are continuous, 


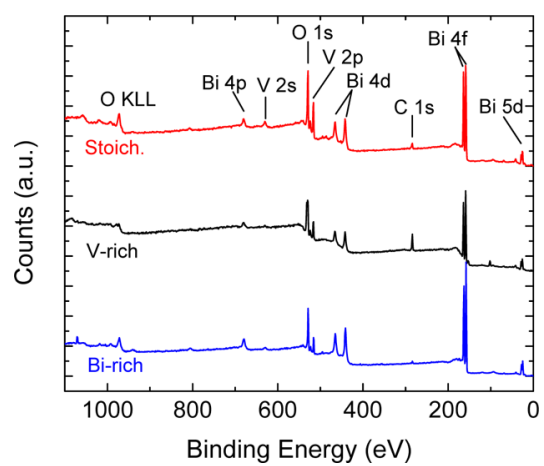

Figure 5. Survey scan X-ray photoelectron spectra from sputtered BVO thin films with different compositions: Bi-rich (blue), V-rich (black), and nearly stoichiometric (red). The elemental components of the films, $\mathrm{Bi}, \mathrm{V}$, and $\mathrm{O}$, along with adventitious $\mathrm{C}$, are observed for all samples.

which is consistent with morphological characterization by SEM (Figure 2).

Figure $6 \mathrm{a}$ and $\mathrm{b}$ shows spectra obtained from the $\mathrm{Bi} 4 \mathrm{f}$ and $\mathrm{V}$ $2 \mathrm{p}$ core level regions. The $\mathrm{Bi} 4 \mathrm{f}$ region is characterized by the
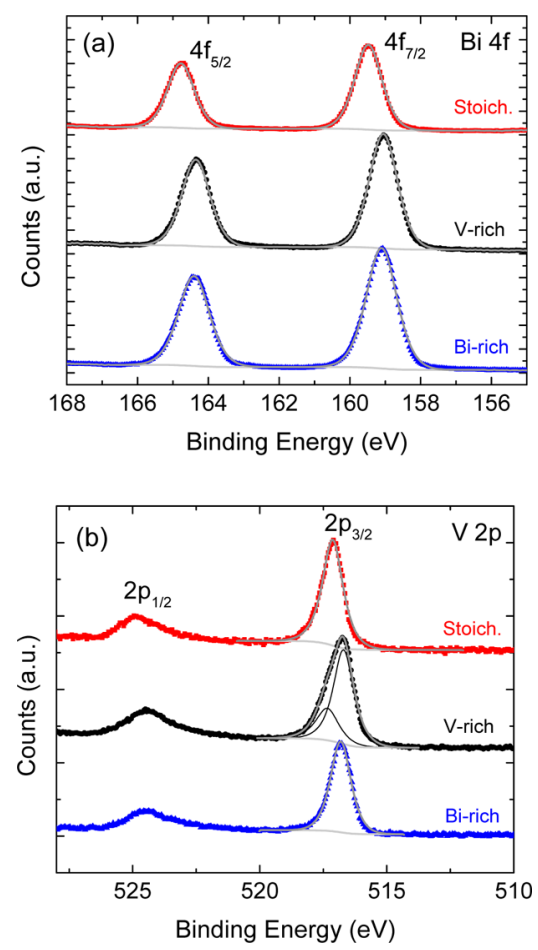

Figure 6. Narrow scan X-ray photoelectron spectra in the Bi $4 \mathrm{f}(\mathrm{a})$ and $\mathrm{V} 2 \mathrm{p}$ (b) core level regions from sputtered BVO thin films with different compositions: Bi-rich (blue triangles), V-rich (black circles), and nearly stoichiometric (red squares). Solid gray lines show the Shirley background and envelope fits. The thin solid lines in $\mathrm{b}$ show the component fits, with the high and low binding energy components assigned to $\mathrm{V}^{5+}$ in $\mathrm{V}_{2} \mathrm{O}_{5}$ and in $\mathrm{BiVO}_{4}$, respectively.

presence of $4 f_{7 / 2}$ and $4 f_{5 / 2}$ components with a spin-orbit splitting of $5.3 \mathrm{eV}$ and the expected branching ratio of 1.0:0.75. Likewise, the $\mathrm{V} 2 \mathrm{p}$ region includes $2 \mathrm{p}_{3 / 2}$ and $2 \mathrm{p}_{1 / 2}$ components with a spin orbit splitting of $\sim 7.6 \mathrm{eV}$. Calculation of the surface atomic composition of each sample was performed using the total $\mathrm{V} 2 \mathrm{p}_{3 / 2}$ and $\mathrm{Bi} 4 \mathrm{f}_{7 / 2}$ spectral intensities, weighted by the corresponding atomic sensitivity factors, and yielded $\mathrm{Bi} / \mathrm{V}$ ratios of 1.9, 0.79, and 0.95 for the Bi-rich, V-rich, and stoichiometric films, respectively. The values for the $\mathrm{V}$-rich and stoichiometric samples are in good agreement with the bulk compositions determined by EDS. However, XPS suggests that samples grown under Bi-rich conditions are characterized by enrichment of $\mathrm{Bi}$ at the surface relative to the bulk. Because $\mathrm{Bi}$ is more volatile than $\mathrm{V}$, it is possible that excess $\mathrm{Bi}$ could migrate to the surface during the postannealing process and either segregate there or evaporate after migration but recondense upon cooling.

In addition to atomic composition, important information about the chemical states of the elemental constituents can be determined from XPS. Fitting of the Bi $4 \mathrm{f}$ spectra demonstrates that each of the spin-orbit split peaks in Figure $6 a$ can be described by a single component, revealing that $\mathrm{Bi}$ is present in a single oxidation state for each sample. For all films, the binding energy position allows assignment to $\mathrm{Bi}^{3+}$, with no observed contribution from $\mathrm{Bi}^{4+} .^{31}$ However, the binding energy position is also observed to shift as a function of composition, with $\mathrm{Bi} 4 \mathrm{f}_{7 / 2}$ binding energies of 159.1, 159.0, and $159.5 \mathrm{eV}$ for Bi-rich, V-rich, and stoichiometric thin films, respectively. Similar composition-dependent binding energy shifts are observed in the V $2 \mathrm{p}$ region (vide infra). Therefore, it is possible to conclude that these shifts are of electronic, rather than chemical, origin. Since core level binding energies are measured relative to the Fermi level position within a material, the spectral position is inherently dependent on the doping type and concentration, with larger core level binding energies for n-type, compared to p-type, material. In the present case, the stoichiometric film is characterized by the largest binding energy, indicating that the Fermi level at the surface of this material is closer to the conduction band than for the offstoichiometric films. We note that the Fermi level position relative to the band edges at the surface can differ from the bulk position due to the presence of a space charge region below the surface of the material. Therefore, XPS results typically provide a lower bound on the differences of the bulk Fermi level positions within the deposited films.

While analysis of the $\mathrm{Bi} 4 \mathrm{f}$ region reveals that $\mathrm{Bi}$ exists in a single chemical environment within each film, the $V 2 p_{3 / 2}$ peak for the V-rich sample (Figure 6b) includes two spectral components at 517.3 and $516.7 \mathrm{eV}$, which can be assigned to $\mathrm{V}^{5+}$ in $\mathrm{V}_{2} \mathrm{O}_{5}$ and $\mathrm{V}^{5+}$ in $\mathrm{BiVO}_{4}$, respectively. ${ }^{31}$ The presence of two spectral components indicates phase segregation within the V-rich film and is consistent with the results from Raman spectroscopy, as well as theoretical predictions for the $\mathrm{Bi}-\mathrm{V}-\mathrm{O}$ ternary phase diagram. ${ }^{32}$ Comparison of the areal contributions of these two phases reveals that the ratio of $\mathrm{V}^{5+}$ in $\mathrm{V}_{2} \mathrm{O}_{5}$ to $\mathrm{V}^{5+}$ in $\mathrm{BiVO}_{4}$ is approximately 0.3 . This is in excellent agreement with the average atomic composition of the film determined via XPS, which indicated a $\mathrm{Bi} / \mathrm{V}$ ratio of 0.79 (or $\mathrm{V} / \mathrm{Bi}$ ratio of 1.27 ), and suggests phase segregation to nearly stoichiometric $\mathrm{BiVO}_{4}$, with excess $\mathrm{V}$ present as $\mathrm{V}_{2} \mathrm{O}_{5}$. The binding energies for $\mathrm{V}^{5+}$ within the Bi-rich, V-rich, and stoichiometric films of 516.8 $\mathrm{eV}, 516.7$, and $517.1 \mathrm{eV}$ are consistent with the differences observed between the $\mathrm{Bi} 4 \mathrm{f}$ peaks arising from differences of Fermi level positions for films of different compositions. While no phase segregation is observed for either the Bi-rich or stoichiometric films, the chemical shift between $\mathrm{BiVO}_{4}$ and $\mathrm{Bi}_{2} \mathrm{VO}_{5.5}$ phases is, to the best of our knowledge, not known, which prevents direct assessment of the homogeneity of Bi-rich films via XPS without a phase-pure reference sample. 
The photoelectrochemical (PEC) performance of the films is summarized in Figure 7. Under anodic bias, both off-

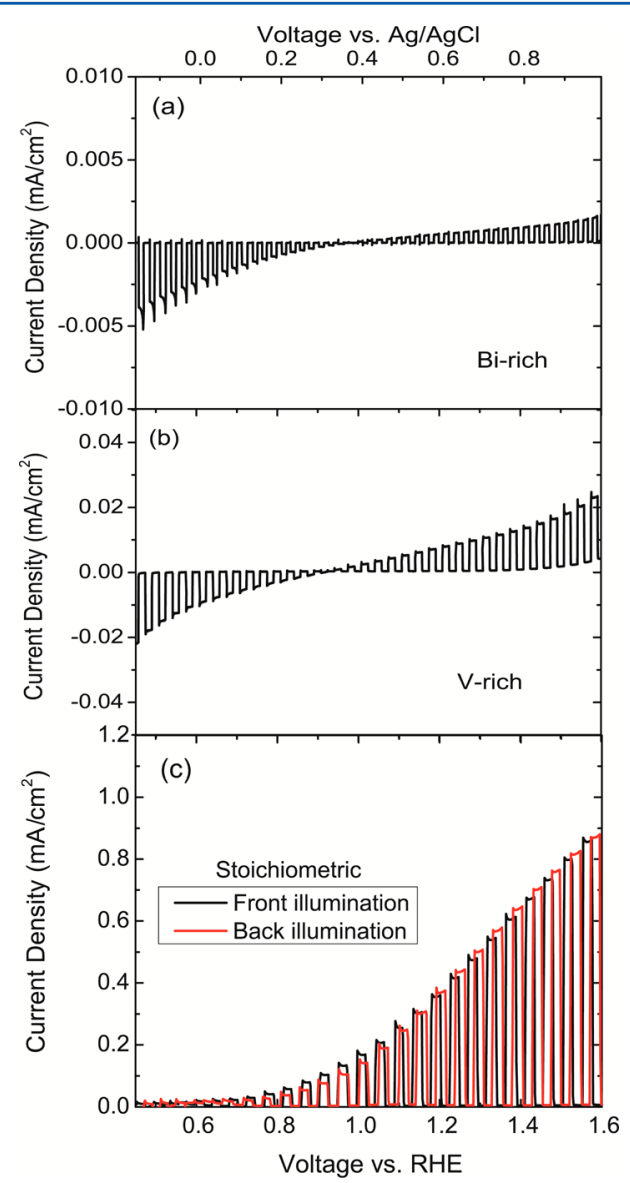

Figure 7. $J-V$ (current density vs voltage) curves from the Bi-rich (a), V-rich (b), and stoichiometric (c) films under chopped AM 1.5 illumination ( 1 sun, $100 \mathrm{~mW} \mathrm{~cm}^{-2}$ ) in $\mathrm{pH} 70.5 \mathrm{M} \mathrm{Na}_{2} \mathrm{SO}_{4}$ in $0.1 \mathrm{M}$ $\mathrm{K}_{2} \mathrm{HPO}_{4}$ buffer solution. The curves from the off-stoichiometric films are the photocurrents arising from front illumination. For the stoichiometric thin film, a comparison between front and back illumination reveals identical photocurrent responses.

stoichiometric films exhibited very low photocurrent densities (Figure $7 \mathrm{a}$ and $\mathrm{b}$ ). For bias $<1 \mathrm{~V}$ vs RHE, there is crossover to a small cathodic current. The conduction band of $\mathrm{BiVO}_{4}$ is lower than the $\mathrm{H}_{2}$ evolution potential, ${ }^{6,33}$ so this current is not due to water reduction involving $\mathrm{BiVO}_{4}$. We tentatively assign this phenomenon to an oxygen reduction reaction. ${ }^{34}$ In contrast, the stoichiometric $\mathrm{BiVO}_{4}$ thin film, which possesses a slight excess of $\mathrm{V}$, exhibits a large and dominant photoanodic current density, with little photocathodic current at negative biases. Indeed, the photocurrent density at OER, $0.5 \mathrm{~mA} \mathrm{~cm}{ }^{-2}$, is among the best reported in the literature for unmodified $\mathrm{BiVO}_{4}$, and the onset potential of approximately $0.4 \mathrm{~V}$ vs RHE is similar to that reported for $\mathrm{BiVO}_{4}$ thin films deposited via solution-based methods. ${ }^{7,8}$

The XPS results give insight into the photoelectrochemical response of the films. The stoichiometric $\mathrm{BiVO}_{4}$ film possesses the largest $\mathrm{V}$ and $\mathrm{B}$ core level binding energies, indicating that the surface Fermi level lies closer to the conduction band than for the off-stoichiometric films. The n-type PEC response shown in Figure $7 \mathrm{c}$ is consistent with this picture. By contrast, the surface Fermi level lies further from the conduction band in both the Bi- and V-rich films. This could be indicative of both $\mathrm{n}$ - and p-type regions in the film, possibly due to phase segregation, which would be consistent with the ambipolar photocurrent response.

The conductivity type differences observed between the offstoichiometric and stoichiometric films partially agree with the defect formation energy calculations published by Yin et al. ${ }^{32}$ While they found that the most influential intrinsic defects on carrier conductivity are oxygen-related defects, the oxygen content in sputtered bismuth vanadate is not studied in the present work. However, their work also pointed out that defects such as V interstitials and V substitution on Bi sites can serve as donors, a situation consistent with our highest performing stoichiometric film with a slight $\mathrm{V}$ enrichment. Likewise, defects such as $B i$ vacancies, $V$ vacancies, and $B i$ substitution on $V$ sites can serve as acceptors and result in p-type doping, which may occur for these off-stoichiometric films. Furthermore, it is possible that $\mathrm{Bi}$ - or $\mathrm{V}$-enrichment may lead to induced defects that serve as hole-trapping sites. As a consequence, photoexcited holes can only be only extracted under high bias. The presence of such trapping sites would explain the observed ptype photocathodic current at lower bias as well as the overall poor PEC performance.

In addition to the relationship between stoichiometry and PEC performance from sputtered $\mathrm{BiVO}_{4}$ films, we also explored differences between front illumination and back illumination. A variety of reports on solution-deposited $\mathrm{BiVO}_{4}$ thin films have found superior photoelectrochemical performance when the material is illuminated from the back. ${ }^{7,8,15}$ This observation has been attributed to poor majority (electron) carrier transport in bulk $\mathrm{BiVO}_{4}$, which is mitigated under back illumination because the transport length from region of most intense photoexcitation is minimized. In contrast, we did not observe a significant difference of photocurrent response between back and front illumination for the case of the $100 \mathrm{~nm}$ thick stoichiometric film, as shown by the $J-V$ curve in Figure $7 \mathrm{c}$.

However, this observation does not necessarily imply that majority carrier (electrons) transport is significantly improved in sputtered $\mathrm{BiVO}_{4}$ films. In fact, after sputter deposition of uniform and dense films of $100 \mathrm{~nm}$ thicknesses, the material remained highly insulating. When we conducted $J-V$ measurements on a thicker film $(200 \mathrm{~nm})$ with the same stoichiometry, we observed a larger photocurrent density under back illumination relative to front illumination, as shown in Figure 8. However, the overall photoactivity was worse than that for the $100 \mathrm{~nm}$ thin film. In addition, we tested thicker films (not shown) and observed reduced photocurrent densities with distinctive, though not necessarily larger, differences between front and back illumination for increasingly thick films. For the thickest films of approximately $500-600 \mathrm{~nm}$, only very tiny photocurrents were generated from both front and back side illumination.

While the enhanced photocurrent density for back illumination is clearly thickness dependent, we find that it is not entirely a consequence of poor electron transport. Rather, it is likely that the observed phenomenon is due to a combined effect from both electron and hole transport. At $100 \mathrm{~nm}$, the thickness for the thin sputtered film may be close to or slightly less than the hole diffusion length in the material. In this circumstance, the holes can readily diffuse toward the surface under either front or back illumination. In this thickness regime, the hole mobility, rather than the electron mobility, dominates the charge extraction efficiency. However, when the 


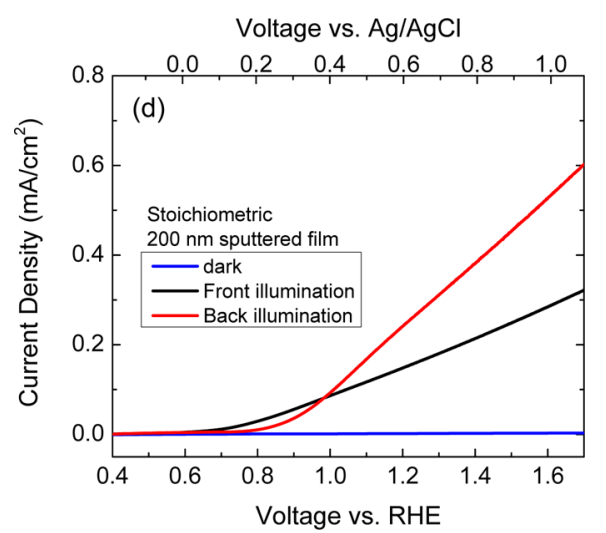

Figure 8. Comparison between $J-V$ curves from a thicker stoichiometric sample $(200 \mathrm{~nm})$ under front and back illumination reveals higher photocurrent densities when the sample is illuminated from the back.

film thickness exceeds the hole diffusion length, holes generated deeper in the film may be trapped or recombine with majority electrons. Thus, in spite of increased photo absorption in thicker films, only the volume of film within the minority carrier diffusion length to the space charge region near the surface contributes to the photocurrent, and electron transport to the ITO contact becomes the limiting factor in the photocurrent density. When the sample is back illuminated, there is a shorter diffusion length for the electrons to reach the contact compared to the case for front illumination. Therefore, the charge extraction efficiency is improved compared to the front illumination, and problems associated with carrier recombination in the bulk are ameliorated. Although the overall photocurrent densities decrease under both front and back illumination due to poor electron transport and inefficient charge separation, the photocurrent density under back illumination suffers less. However, as the film thickness increases, the efficiency of charge migration of both the majority carriers to the contact and minority carriers to the surface is reduced. For the thickest films, neither front nor back illumination is effective, and only negligible photocurrents are generated. Since previously published thin film synthesis methods for $\mathrm{BiVO}_{4}$ were primarily solution based and tended to create more porous morphologies compared to sputtering, the film thickness dependence on PEC performance in those materials was not as closely correlated with the hole diffusion length.

As implied in the previous paragraph, efficient charge carrier separation within the semiconductor is of critical importance for PEC applications. One effective method of reducing carrier recombination, and thus enhancing separation efficiency, is to add a hole-blocking layer, which prevents holes from migrating to the back contact and recombining with the electrons at the electrical contact. It has been established that metal oxides such as $\mathrm{WO}_{3}{ }^{31,35,36}$ and $\mathrm{SnO}_{2}{ }^{19,35}$ possess band edge energies that are suitably aligned with those of $\mathrm{BiVO}_{4}$ for facilitating electron transport but hindering hole transport to the back contact, thus promoting directional hole transport to the electrolyte. Therefore, we investigated the effect of a hole-blocking layer on the photoelectrochemical performance of sputtered stoichiometric $\mathrm{BiVO}_{4}$ thin films by adding a $\mathrm{WO}_{3}$ layer underneath the $\mathrm{BiVO}_{4}$. A $100 \mathrm{~nm}$ thick $\mathrm{WO}_{3}$ film was first deposited by reactive sputtering on ITO-coated glass. Then, a stoichiometric (slightly enriched in V) $100 \mathrm{~nm} \mathrm{BiVO} 4$ thin film was reactively sputtered on top of the $\mathrm{WO}_{3}$ film. Figure 9 shows a comparison of $J-V$ curves from $\mathrm{BiVO}_{4}$ with and

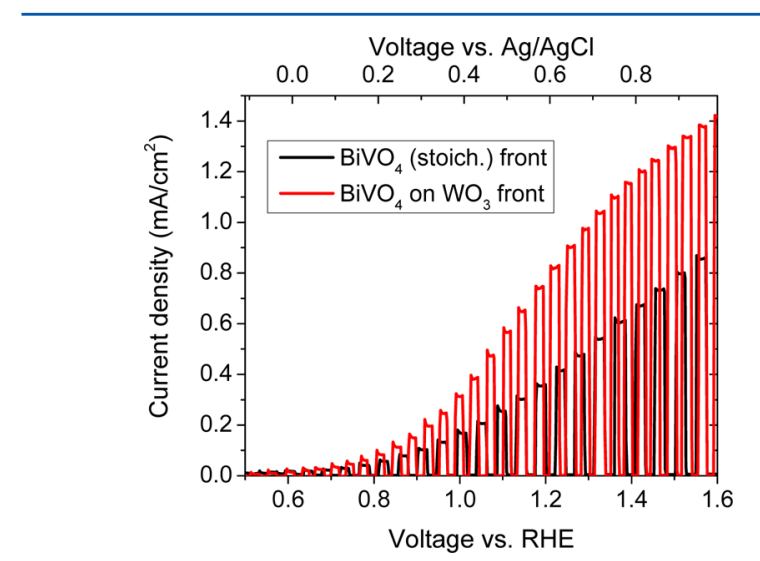

Figure 9. $J-V$ (current density vs voltage) curves of $\mathrm{BiVO}_{4}$ thin films with and without a $\mathrm{WO}_{3}$ hole-blocking layer. The samples were tested in a three electrode configuration under front side chopped illumination with an AM1.5, $100 \mathrm{~W} / \mathrm{cm}^{2}$ light source and in $\mathrm{pH} 7$ buffer solution.

without a $\mathrm{WO}_{3}$ hole-blocking layer under chopped front side illumination. Strikingly, an improvement of the photocurrent density by nearly a factor of 2 at $1.2 \mathrm{~V}$ vs RHE can be achieved by the addition of the $\mathrm{WO}_{3}$ underlayer. Furthermore, in the case of the $\mathrm{BiVO}_{4}$ thin film with a $\mathrm{WO}_{3}$ underlayer, PEC measurements reveal that front illumination yields larger photocurrent densities than back illumination.

We considered the possibility that the $\mathrm{WO}_{3}$ layer might contribute to the photocurrent. The PEC performance of the $\mathrm{WO}_{3}$ layer by itself is shown in Figure S1(Supporting Information); the observed photocurrent is more than an order of magnitude smaller than that of the double layer structure. We also compare in Figure S3 (Supporting Information) the transmission spectra of a $100 \mathrm{~nm} \mathrm{BiVO}_{4}$ film and a $100 \mathrm{~nm} \mathrm{BiVO}_{4} / 100 \mathrm{~nm} \mathrm{WO}_{3}$ structure. The transmission spectra are nearly identical; in the double layer structure, most of the light is absorbed in the $\mathrm{BiVO}_{4}$ layer.

Figure 10 displays the IPCE of the $\mathrm{BiVO}_{4}$ thin film with a $\mathrm{WO}_{3}$ underlayer, a result in close agreement with the inset

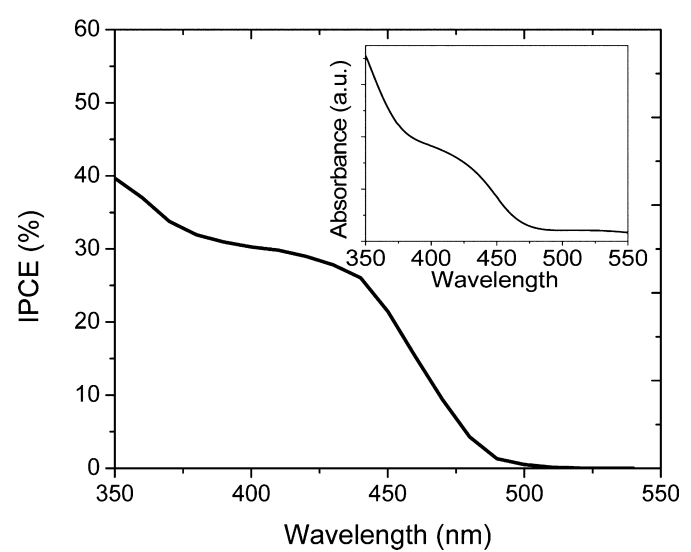

Figure 10. IPCE spectrum of a $\mathrm{BiVO}_{4}$ thin film with a $100 \mathrm{~nm}$ thick $\mathrm{WO}_{3}$ hole-blocking layer on an ITO substrate with an inset of optical absorption spectrum of the film. The sample was held at $1.2 \mathrm{~V}$ versus RHE in a three electrode configuration and was illuminated from the front side in $\mathrm{pH} 7$ buffer solution. 
absorbance spectrum of the film measured. The IPCE exhibits a photocurrent onset near $490 \mathrm{~nm}$, which rises steeply to IPCE values of $30 \%$ to $40 \%$ at wavelengths shorter than $\sim 450 \mathrm{~nm}$. The steep IPCE decrease at wavelengths larger than 440-450 $\mathrm{nm}$ is consistent with previous reports, 77,19 and is a consequence of above-bandgap optical absorption. However, the small tail of IPCE and absorption response out to $\sim 500 \mathrm{~nm}$ is due to weak light absorption at the band edge, which may suggest that $\mathrm{BiVO}_{4}$ possesses an indirect bandgap that is slightly narrower than its direct transition ${ }^{19}$ or that band edge tail states induced by regions of disorder contribute to the photoelectrochemical response. Figure S4 (Supporting Information) shows Tauc plots of $\mathrm{BiVO}_{4}$ films which are consistent with this picture.

\section{CONCLUSIONS}

We synthesized high quality $\mathrm{BiVO}_{4}$ thin films by reactive cosputtering for the first time and explored the influence of the $\mathrm{Bi} / \mathrm{V}$ ratio on structure, morphology, and PEC performances. For Bi-rich and V-rich films, they showed some degree of phase separation and both weak photoanodic and photocathodic current responses. Near-stoichiometric $\mathrm{BiVO}_{4}$ (with slight V rich) showed a photocathodic response with a much higher current density. We also discussed the influence of front illumination versus back illumination, finding that the influence of illumination side was film thickness dependent and might be a combined effect from both electron and hole transport. In addition, we improved carrier separation by adding a $\mathrm{WO}_{3}$ hole-blocking layer. In the future, we will work on the further improvement of $\mathrm{BiVO}_{4}$ thin films for PEC application such as improving the conductivity by doping and loading OER catalysts, as well as using high quality sputtered $\mathrm{BiVO}_{4}$ thin films as platforms for fundamental studies of this material.

\section{ASSOCIATED CONTENT}

\section{(S Supporting Information}

Photoelectrochemical testing of sputtered $\mathrm{WO}_{3}$ photoanodes; photoelectrochemical stability of $\mathrm{BiVO}_{4} / \mathrm{WO}_{3}$ photoanodes; optical characterization of $\mathrm{BiVO}_{4}$ and $\mathrm{BiVO}_{4} / \mathrm{WO}_{3}$ photoanodes; cross-sectional SEM image of $\mathrm{BiVO}_{4} / \mathrm{WO}_{3}$ layers on ITO coated glass substrate. This material is available free of charge via the Internet at http://pubs.acs.org.

\section{AUTHOR INFORMATION}

\section{Corresponding Author}

*Joint Center for Artificial Photosynthesis, Lawrence Berkeley National Laboratory, MS62R0203, 1 Cyclotron Road, Berkeley, CA 94720. Phone: 1-510-486-6715. Fax: 1-510-486-4995. Email: JWAger@lbl.gov.

\section{Notes}

The authors declare no competing financial interest.

\section{ACKNOWLEDGMENTS}

This material is based upon work performed by the Joint Center for Artificial Photosynthesis, a DOE Energy Innovation Hub, supported through the Office of Science of the U.S. Department of Energy under Award Number DE-SC0004993. E.A.L. also acknowledges fellowship support from Marie Curie Actions Program.

\section{ABBREVIATIONS}

PEC, photoelectrochemical; RHE, reversible hydrogen electrode; $J-V$, current-voltage; $J_{\mathrm{SC}}$, short-circuit current; IPCE, incident photon to charge conversion efficiency; SEM, scanning electron microscope; XRD, X-ray diffraction

\section{REFERENCES}

(1) Kudo, A.; Ueda, K.; Kato, H.; Mikami, I. Photocatalytic $\mathrm{O}_{2}$ Evolution under Visible Light Irradiation on $\mathrm{BiVO}_{4}$ in Aqueous $\mathrm{AgNO}_{3}$ Solution. Catal. Lett. 1998, 53, 229-230.

(2) Sayama, K.; Nomura, A.; Arai, T.; Sugita, T.; Abe, R.; Yanagida, M.; Oi, T.; Iwasaki, Y.; Abe, Y.; Sugihara, H. Photoelectrochemical Decomposition of Water into $\mathrm{H}_{2}$ and $\mathrm{O}_{2}$ on Porous $\mathrm{BiVO}_{4}$ Thin-Film Electrodes under Visible Light and Significant Effect of Ag Ion Treatment. J. Phys. Chem. B 2006, 110, 11352-11360.

(3) Long, M.; Cai, W. M.; Cai, J.; Zhou, B. X.; Chai, X. Y.; Wu, Y. H. Efficient Photocatalytic Degradation of Phenol over $\mathrm{Co}_{3} \mathrm{O}_{4} / \mathrm{BiVO}_{4}$ Composite under Visible Light Irradiation. J. Phys. Chem. B 2006, 110, 20211-20216.

(4) Kohtani, S.; Koshiko, M.; Kudo, A.; Tokumura, K.; Ishigaki, Y.; Toriba, A.; Hayakawa, K.; Nakagaki, R. Photodegradation of 4alkylphenols Using $\mathrm{BiVO}_{4}$ Photocatalyst under Irradiation with Visible Light from A Solar Simulator. Appl. Catal., B 2003, 46, 573-586.

(5) Kudo, A.; Miseki, Y. Heterogeneous Photocatalyst Materials for Water Splitting. Chem. Soc. Rev. 2009, 38, 253-278.

(6) Park, Y.; McDonald, K. J.; Choi, K. S. Progress in Bismuth Vanadate Photoanodes for Use in Solar Water Oxidation. Chem. Soc. Rev. 2013, 42, 2321-2337.

(7) Abdi, F. F.; van de Krol, R. Nature and Light Dependence of Bulk Recombination in Co-Pi-Catalyzed $\mathrm{BiVO}_{4}$ Photoanodes. J. Phys. Chem. C 2012, 116, 9398-9404.

(8) Luo, W. J.; Yang, Z. S.; Li, Z. S.; Zhang, J. Y.; Liu, J. G.; Zhao, Z. Y.; Wang, Z. Q.; Yan, S. C.; Yu, T.; Zou, Z. G. Solar Hydrogen Generation from Seawater with A Modified $\mathrm{BiVO}_{4}$ Photoanode. Energy Environ. Sci. 2011, 4, 4046-4051.

(9) Tong, L.; Iwase, A.; Nattestad, A.; Bach, U.; Weidelener, M.; Gotz, G.; Mishra, A.; Bauerle, P.; Amal, R.; Wallace, G. G.; et al. Sustained Solar Hydrogen Generation Using a Dye-Sensitised $\mathrm{NiO}$ Photocathode $/ \mathrm{BiVO}_{4}$ Tandem Photo-electrochemical Device. Energy Environ. Sci 2012, 5, 9472-9475.

(10) Zhang, L.; Chen, D. R.; Jiao, X. L. Monoclinic Structured BiVO Nanosheets: Hydrothermal Preparation, Formation Mechanism, and Coloristic and Photocatalytic Properties. J. Phys. Chem. B 2006, 110, 2668-2673.

(11) Zhou, L.; Wang, W. Z.; Zhang, L.; Xu, H. L.; Zhu, W. Singlecrystalline $\mathrm{BiVO}_{4}$ Microtubes with Square Cross-sections: Microstructure, Growth Mechanism, and Photocatalytic Property. J. Phys. Chem. C 2007, 111, 13659-13664.

(12) Kudo, A.; Omori, K.; Kato, H. A Novel Aqueous Process for Preparation of Crystal Form-Controlled and Highly Crystalline $\mathrm{BiVO}_{4}$ Powder from Layered Vanadates at Noom Temperature and Its Photocatalytic and Photophysical Properties. J. Am. Chem. Soc. 1999, 121, 11459-11467.

(13) Abdi, F. F.; Firet, N.; van de Krol, R. Efficient $\mathrm{BiVO}_{4}$ Thin Film Photoanodes Modified with Cobalt Phosphate Catalyst and W-doping. ChemCatChem 2013, 5, 490-496.

(14) Li, Z. S.; Luo, W. J.; Zhang, M. L.; Feng, J. Y.; Zou, Z. G. Photoelectrochemical Cells for Solar Hydrogen Production: Current State of Promising Photoelectrodes, Methods to Improve Their Properties, and Outlook. Energy Environ. Sci. 2013, 6, 347-370.

(15) Seabold, J. A.; Choi, K. S. Efficient and Stable Photo-Oxidation of Water by a Bismuth Vanadate Photoanode Coupled with an Iron Oxyhydroxide Oxygen Evolution Catalyst. J. Am. Chem. Soc. 2012, 134, 2186-2192.

(16) Ding, C. M.; Shi, J. Y.; Wang, D. G.; Wang, Z. J.; Wang, N.; Liu, G. J.; Xiong, F. Q.; Li, C. Visible Light Driven overall Water Splitting Using Cocatalyst/BiVO 4 Photoanode with Minimized Bias. Phys. Chem. Chem. Phys. 2013, 15, 4589-4595. 
(17) Berglund, S. P.; Flaherty, D. W.; Hahn, N. T.; Bard, A. J.; Mullins, C. B. Photoelectrochemical Oxidation of Water Using Nanostructured $\mathrm{BiVO}_{4}$ Films. J. Phys. Chem. C 2011, 115, 3794-3802.

(18) Jia, Q. X.; Iwashina, K.; Kudo, A. Facile Fabrication of An Efficient $\mathrm{BiVO}_{4}$ Thin Film Electrode for Water Splitting under Visible Light Irradiation. Proc. Natl. Acad. Sci. U.S.A. 2012, 109, 11564-11569.

(19) Liang, Y. Q.; Tsubota, T.; Mooij, L. P. A.; van de Krol, R. Highly Improved Quantum Efficiencies for Thin Film $\mathrm{BiVO}_{4}$ Photoanodes. J. Phys. Chem. C 2011, 115, 17594-17598.

(20) Saito, R.; Miseki, Y.; Sayama, K. Highly Efficient Photoelectrochemical Water Splitting Using a Thin Film Photoanode of $\mathrm{BiVO}_{4} / \mathrm{SnO}_{2} / \mathrm{WO}_{3}$ Multi-composite in A Carbonate Electrolyte. Chem. Commun. 2012, 48, 3833-3835.

(21) Berglund, S. P.; Rettie, A. J. E.; Hoang, S.; Mullins, C. B. Incorporation of $\mathrm{Mo}$ and $\mathrm{W}$ into Nanostructured $\mathrm{BiVO}_{4}$ Films for Efficient Photoelectrochemical Water Oxidation. Phys. Chem. Chem. Phys. 2012, 14, 7065-7075.

(22) Chen, L.; Graham, M. E.; Li, G. H.; Gray, K. A. Fabricating Highly Active Mixed Phase $\mathrm{TiO}_{2}$ Photocatalysts by Reactive DC Magnetron Sputter Deposition. Thin Solid Films 2006, 515, 11761181.

(23) Di Franco, F.; Santamaria, M.; Di Quarto, F.; Tsuji, E.; Habazaki, H. The Influence of Nitrogen Incorporation on the Optical Properties of Anodic $\mathrm{Ta}_{2} \mathrm{O}_{5}$. Electrochim. Acta 2012, 59, 382-386.

(24) Marsen, B.; Miller, E. L.; Paluselli, D.; Rocheleau, R. E. Progress in Sputtered Tungsten Trioxide for Photoelectrode Applications. Int. J. Hydrogen. Energy 2007, 32, 3110-3115.

(25) Fedorov, V. I.; Davydov, I. Y. Thermoelectric Properties of Vanadium, Bismuth, and Antimony Oxides in the Temperature Interval 500-1500 Degree-K. High Temp. 1978, 16, 654-660.

(26) Chen, Z. B.; Jaramillo, T. F.; Deutsch, T. G.; KleimanShwarsctein, A.; Forman, A. J.; Gaillard, N.; Garland, R.; Takanabe, K.; Heske, C.; Sunkara, M.; et al. Accelerating Materials Development for Photoelectrochemical Hydrogen Production: Standards for Methods, Definitions, and Reporting Protocols. J. Mater. Res. 2010, 25, 3-16.

(27) Tokunaga, S.; Kato, H.; Kudo, A. Selective Preparation of Monoclinic and Tetragonal $\mathrm{BiVO}_{4}$ with Scheelite Structure and Their Photocatalytic Properties. Chem. Mater. 2001, 13, 4624-4628.

(28) Yu, J. Q.; Kudo, A. Effects of Structural Variation on the Photocatalytic Performance of Hydrothermally Synthesized $\mathrm{BiVO}_{4}$. Adv. Funct. Mater. 2006, 16, 2163-2169.

(29) Dall'Antonia, L. H.; de Tacconi, N. R.; Chanmanee, W.; Timmaji, H.; Myung, N.; Rajeshwar, K. Electrosynthesis of Bismuth Vanadate Photoelectrodes. Electrochem. Solid State Lett. 2010, 13, D29-D32.

(30) Barreca, D.; Depero, L. E.; Di Noto, V.; Rizzi, G. A.; Sangaletti, L.; Tondello, E. Thin Films of Bismuth Vanadates with Modifiable Conduction Properties. Chem. Mater. 1999, 11, 255-261.

(31) Su, J.; Zou, X. X.; Li, G. D.; Wei, X.; Yan, C.; Wang, Y. N.; Zhao, J.; Zhou, L. J.; Chen, J. S. Macroporous $\mathrm{V}_{2} \mathrm{O}_{5}-\mathrm{BiVO}_{4}$ Composites: Effect of Heterojunction on the Behavior of Photogenerated Charges. J. Phys. Chem. C 2011, 115, 8064-8071.

(32) Yin, W. J.; Wei, S. H.; Al-Jassim, M. M.; Turner, J.; Yan, Y. F. Doping Properties of Monoclinic $\mathrm{BiVO}_{4}$ Studied by First-Principles Density-Functional Theory. Phys. Rev. B 2011, 83.

(33) Chen, S. Y.; Wang, L. W. Thermodynamic Oxidation and Reduction Potentials of Photocatalytic Semiconductors in Aqueous Solution. Chem. Mater. 2012, 24, 3659-3666.

(34) Lin, Y. J.; Xu, Y.; Mayer, M. T.; Simpson, Z. I.; McMahon, G.; Zhou, S.; Wang, D. W. Growth of p-Type Hematite by Atomic Layer Deposition and Its Utilization for Improved Solar Water Splitting. J. Am. Chem. Soc. 2012, 134, 5508-5511.

(35) Chatchai, P.; Murakami, Y.; Kishioka, S. Y.; Nosaka, A. Y.; Nosaka, Y. FTO $/ \mathrm{SnO}_{2} / \mathrm{BiVO}_{4}$ Composite Photoelectrode for Water Oxidation under Visible Light Irradiation. Electrochem. Solid State Lett. 2008, 11, H160-H163.

(36) Hong, S. J.; Lee, S.; Jang, J. S.; Lee, J. S. Heterojunction $\mathrm{BiVO}_{4} /$ $\mathrm{WO}_{3}$ Electrodes for Enhanced Photoactivity of Water Oxidation. Energy Environ. Sci. 2011, 4, 1781-1787. 